\title{
SLM tooling for die casting with conformal cooling channels
}

\author{
Antonio Armillotta*, Raffaello Baraggi \\ Dipartimento di Meccanica, Politecnico di Milano \\ Via La Masa 1, 20156 Milano, Italy \\ Simone Fasoli \\ Bruschi SpA \\ Via Mendosio 26, 20081 Abbiategrasso (MI), Italy \\ * Corresponding author: \\ e-mail: antonio.armillotta@polimi.it \\ tel.: +3902 23998296 \\ fax: +3902 23998585
}

\begin{abstract}
The paper reports an experimental study of die-casting dies with conformal cooling fabricated by direct-metal additive techniques. The main objective is to compare the benefits and limitations of the application to what has been widely discussed in literature in the context of plastics injection molding. Selective laser melting was used to fabricate an impression block with conformal cooling channels, designed according to part geometry with the aid of process simulation. The tool was used in the manufacture of sample batches of zinc alloy castings, after being fitted on an existing die in place of a machined impression block with conventional straight-line cooling channels. Different combinations of process parameters were tested to exploit the improved performance of the cooling system. Test results show that conformal cooling improves the surface finish of castings due to a reduced need of spray cooling, which is allowed by a higher and more uniform cooling rate. Secondary benefits include reduction of cycle time and shrinkage porosity.
\end{abstract}

\section{Keywords}

Selective laser melting; rapid tooling; die casting; conformal cooling; spray cooling; surface finish. 


\title{
SLM tooling for die casting with conformal cooling channels
}

\begin{abstract}
The paper reports an experimental study of die-casting dies with conformal cooling fabricated by direct-metal additive techniques. The main objective is to compare the benefits and limitations of the application to what has been widely discussed in literature in the context of plastics injection molding. Selective laser melting was used to fabricate an impression block with conformal cooling channels, designed according to part geometry with the aid of process simulation. The tool was used in the manufacture of sample batches of zinc alloy castings, after being fitted on an existing die in place of a machined impression block with conventional straight-line cooling channels. Different combinations of process parameters were tested to exploit the improved performance of the cooling system. Test results show that conformal cooling improves the surface finish of castings due to a reduced need of spray cooling, which is allowed by a higher and more uniform cooling rate. Secondary benefits include reduction of cycle time and shrinkage porosity.
\end{abstract}

\section{Keywords}

Selective laser melting; rapid tooling; die casting; conformal cooling; spray cooling; surface finish.

\section{INTRODUCTION}

Direct-metal additive manufacturing techniques [1] are increasingly used to build tools for the serial production of plastic and metal components. Their choice was initially intended as a rapid tooling option, which could help to reduce time-to-market and increase product competitiveness. It has been recognized, however, that they enable much bigger improvements on process performance and product properties.

The most evident example of such opportunities is plastics injection molding, where steel tools for final production have been fabricated by several additive techniques. The response time of involved process chains is often comparable to traditional moldmaking practice due to the need of secondary operations such as CNC machining, EDM, thermal treatments, grinding and polishing. Much more valued in those process chains is the chance to provide molds with conformal cooling channels as an alternative of conventional straight-line channels made by deep drilling. During the injection molding process, conformal channels allow a more effective and uniform heat transfer from the resin, thus reducing cycle time and shrinkage defects such as warpage and sink marks [2].

The present work aims at verifying if similar benefits can also be achieved for metal die casting, 
where applications of additive techniques are less studied. It could be argued that an improved cooling system is likely to be less profitable for die casting, as the cooling phase takes a lower fraction of cycle time and material properties are less prone to shrinkage defects. Yet it is interesting to evaluate such differences and investigate on possible additional benefits not seen in injection molding.

For this purpose, an experimental study has been conducted at Bruschi SpA (Abbiategrasso, Italy), a supplier of die castings for several manufacturing sectors. A die for a zinc alloy casting was modified for the use of an additive technique (selective laser melting) and provided with conformal cooling channels. The die was tested on a die-casting machine, where process parameters were tuned for the new cooling system and improvements were evaluated in terms of productivity and cost. Castings were inspected in order to evaluate possible improvements in surface finish and shrinkage porosity.

The remainder of the paper is organized as follows. Section 2 recalls some literature results about conformal channels for injection molding and cooling issues for die casting. Section 3 describes the reference case and its relevance to the objective of the work. The design and fabrication of the die with conformal cooling channels are described in sections 4 and 5. Results of process tests and inspections of castings are reported in section 6 and discussed from an application viewpoint in the conclusions of section 7 .

\section{BACKGROUND}

Studies on conformal cooling channels in injection molds have been recently reviewed in [2]. They usually refer to the manufacture of parts having deep recesses with nonstandard shapes, for which conventional straight-line channels cannot be placed close to mold cavity and commercially available baffles or bubblers cannot be used. Conformal channels are designed with intricate layouts to match the geometry of mold cavities, and with noncircular and variable sections in order to finely adjust cooling conditions. In most cases, mold blocks with conformal channels are fabricated in production tool materials (hot-work or stainless steels) by means of direct-metal additive techniques. As detailed below, specific design criteria for the cooling system have been developed from experimental tests on different techniques.

In a pioneering work, the $3 \mathrm{D}$ printing technique was used on stainless steel powders with a polymer binder and secondary operations including debinding, sintering, infiltration with bronze and CNC/EDM finishing [3]. The main technical issues identified, and later confirmed for other techniques, included the removal of unbinded powder from cooling channels and the protection of channels from infiltration. A suitable sizing of channels helped to solve these problems and to optimize heat transfer with the help of analytic modeling and numerical simulation. Compared to a conventional cooling system, it was shown that conformal channels reduce mold temperature in both 
average values and variation along the molding cycle, and allow to reach thermal steady-state conditions in a shorter time. In [4], a thorough analysis of conformal cooling performance led to a systematic procedure for sizing and layout design considering a comprehensive set of thermal, structural and manufacturing constraints.

In [5], the selective laser sintering technique was first used on powders of hot-work and stainless steels with polymer coating. Required secondary operations were debinding, sintering, infiltration and possible EDM finishing. Powder removal and infiltration issues turned out to be more difficult to solve and required channels of larger cross section. The industrial deployment of this process chain was later discussed in [6]. More recently, the process was improved in [7] through the use of a different hotwork steel, the development of a new way of removing powder from channels (impression blocks split into pieces to be brazed during the infiltration phase) and the provision of a small allowance for highspeed CNC milling. Another experience on the same technique is reported in [8]. Variations of the laser sintering process based on uncoated metal powders (direct metal laser sintering, selective laser melting) are discussed in some commercial reports $[9,10]$, which point out the chance of partially or totally eliminating debinding, post-sintering and infiltration phases. A similar simplification of the process chain was achieved by using the electron beam melting technique on hot-work steel powders with CNC finishing [11].

Other process options were attempted for conformally cooled molds. A technique similar to direct metal deposition was tested in [12]: the process is hybrid since it uses bent copper tubes which are placed in CNC-milled slots and later cladded by tool steel, with CNC/EDM finishing and polishing as secondary operations. Lamination techniques from laser or abrasive-waterjet cut steel sheet are reported in [13] and, for applications on thermoforming molds, in [14-17]. Prototype injection molds were fabricated by epoxy tooling with bent copper tubes [18] and by spray-metal techniques on sacrificial cores in soluble material [19]. Bent copper tubes were also used on impression blocks fabricated in multiple CNC machined pieces [20].

Conformal channels are also regarded as essential for rapid thermal cycling, an innovative thermal conditioning strategy for injection molds which consists in heating the cavity during filling (to avoid early freezing of plasticized resin) and cooling it quickly during the rest of the cycle. Recent studies in that direction include [21-23].

Apart from experimental studies, further attempts were made to improve the design of conformal channels. The automated generation of their layout from part geometry was studied in [24-27]. Methods for the optimal sizing of channel sections were proposed in [28-32]. Innovative concepts to improve heat transfer were also proposed and validated by analytic modeling and simulation; they include unusual shapes of channel sections [33] and hydro-abrasive treatments to increase the roughness of channel surfaces [34]. Thermal simulations were also reported within case studies in [35- 
38].

Conformal cooling was first applied to metal die casting in [39]. A multiple-impression die was fabricated from steel laminations and tested in the manufacture of aluminum castings. As part geometry did not pose special cooling difficulties, conformal channels were only provided to ease solidification in the shot sleeve and to reduce average die temperature with no special focus on cycle time reduction. An innovative design of conformal channels, suitable to either additive and subtractive techniques, was patented in [40]: heat transfer was improved by increasing coolant flow rate through channel with larger-than-usual cross sections.

Additive techniques were used for die-casting dies with conventional cooling channels. Initial concerns were related to the higher thermal stresses and to possible loss of accuracy and structural integrity; such issues were succesfully verified on direct metal laser sintering [41], direct metal deposition [42] and spray-metal processes for soft tools [43].

Apart from the choice of additive techniques, the design of conventional cooling channels for diecasting dies has been treated in several papers. The heat transfer between casting and coolant was modeled and measured in [44]. The effect of boiling in cooling channels was analyzed in [45] to propose new criteria for the optimization of channel layout. The thermal distortion of the die during the die casting cycle was simulated in [46] to optimize some design variables related to cooling channels.

As it will be confirmed in this paper, the design of cooling channels for die casting cannot ignore the use of die lubricant to remove heat from the impression, usually referred to as spray cooling. As pointed out in [47], thermal shocks during lubricant application can damage both the impression and the casting; to keep them at a minimum, the needed amount of lubricant should be reduced by oversizing the cooling channels. In [48], the heat transfer from die impression to lubricant was analyzed under different combinations of spray cooling parameters (lubricant pressure and composition, die temperature). Heat transfer during lubricant spraying was measured by several techniques as described in [49-50].

In [51], the use of computational fluid dynamics (CFD) simulation is reported along the development cycle of a die casting process. Although the study did not involve the use of conformal channels and additive techniques, it has some interest here due to the choice of the reference case: the casting is similar to the one chosen in the present paper, although in a different design with less cooling difficulties.

\section{CASE STUDY AND OBJECTIVES}

This work will refer to the manufacture of a handle cover in zinc alloy Zamak 5 (ASTM AC 41A, UNS Z35531), whose outside shape and dimensions are shown in Fig. 1. The part has a hollow shape 
with an average wall thickness of $1.5 \mathrm{~mm}$ and internal bosses with complex profile and some blind holes (not shown in figure). It weighs $0.135 \mathrm{~kg}$ and is manufactured in large quantity by a fourimpression die on a 1250-kN hot-chamber die-casting machine. Molten metal is injected under vacuum into the die at $410^{\circ} \mathrm{C}$, with an overheating of $22^{\circ} \mathrm{C}$ with respect to the liquidus temperature of the alloy. Cycle time is $18 \mathrm{~s}$, of which $4.5 \mathrm{~s}$ are taken by the cooling phase. Secondary operations after die casting include trimming, tapping of holes, tumble finishing, acid dipping and painting.

The die is made up of two impression blocks built in AISI H13 (DIN 1.2344) hot-work steel by CNC milling and EDM. Each block has a plate size of $180 \times 160 \mathrm{~mm}$ and a total height of $95 \mathrm{~mm}$, and includes two impressions with tangential runner gates. Fig. 2 shows the ejector die impression block which includes large stationary cores, small-diameter core pins, vacuum channels and a conventionaltype cooling system. The latter is made of straight-line channels with diameter of $6 \mathrm{~mm}$ and spacing of $20-25 \mathrm{~mm}$; as it is usual with drilled channels, their layout is confined to a plane at a relatively long distance to impression surfaces, and is also constrained by the presence of many ejector pins. The channels in the cover die impression block have a similar layout, which is obviously less critical with respect to cooling performance. Different coolants are used for the two die halves: water at $20^{\circ} \mathrm{C}$ for the ejector die to maximize heat transfer, oil at $80^{\circ} \mathrm{C}$ for the cover die to reduce thermal shocks and avoid macroscopic surface defects on castings.

As a first consequence of the limited cooling rate allowed by conventional channels, the bosses on the backside of the casting cool more slowly than the outside walls. Also due to the presence of slightly thicker zones between adjacent holes, the bosses are still hot when the casting is removed from the die and can be damaged by the pressure of ejector pins. Cycle time could be increased to avoid defects, but this would affect productivity and operating cost and is usually not done at the expense of a possibly higher scrap rate.

A second issue is the occurrence of local surface defects of the type shown in Fig. 3a. These are called surface waves and have the appearance of short wavy lines spread along part surface. They are acceptable if the casting is to be painted, but exclude alternative high-gloss surface treatments such as electroplating, which are sometimes specified for this type of part.

Surface waves are generally interpreted as welding lines between small areas of casting surface which freeze early during die filling. As noted through visual inspection of a sample of 10 parts, surface waves are located in the zones of casting surface shown in Fig. 3b. This can be explained considering that zones $\mathrm{A}$ and $\mathrm{B}$ are the farthest from the injection gate and zone $\mathrm{C}$ is close to the vacuum channel; the injected metal is thus likely to have a lower temperature and freeze prematurely when reaching these points on the impression.

A wrong choice of process parameters is usually blamed for the occurrence of surface waves. Conditions that could cause early freezing include a low die temperature, a relatively long filling time 
and a large amount of lubricant; the latter could also leave residues at the interface to the casting with possible additional consequences on its surface finish. All these effects, however, had been kept at a minimum in this case: die temperature is the maximum allowed by specified productivity levels and filling time is the minimum allowed by the machine. More importantly, the amount of die lubricant cannot be reduced any further because spray cooling must compensate the limited performance of the conventional cooling system.

To gain insights on the causes of surface defects, CFD simulations were done by the Flow 3D software in collaboration with a partner company (XC Engineering, Cantù, Italy). The geometry of an individual die impression with its cooling channels was acquired from STL models generated by a CAD solid modeler and then meshed into cubic cells with size of 0.7-0.8 mm. Either filling and solidification were simulated under actual process conditions except for spray cooling.

In the simulation of filling, the occurrence of spray jets was observed in the wall opposite to the injection gate but also in other zones of the impression, with no further specific effect on the zones affected by surface waves. In the simulation of the solidification phase, it was confirmed that different zones of the casting have much different cooling rate: while the thin walls freeze in nearly $1 \mathrm{~s}$ (with no significant delay on the gate side), the thicker bosses take almost $4 \mathrm{~s}$ to freeze. Fig. 4 shows the distribution of temperatures in the casting (in $\mathrm{K}$ ) at nearly half of programmed cooling time. As it is easily noted, the temperature in the difficult-to-cool zones exceeds the temperature of the thin walls by almost $100^{\circ} \mathrm{C}$. Average die temperatures were estimated by simulation of a sufficient number of cycles: from a minimum of $140-150^{\circ} \mathrm{C}$ on the cover die side, they increase to $220-230^{\circ} \mathrm{C}$ within the main core on the ejector die, to $260-280^{\circ} \mathrm{C}$ in the thicker bosses and to as much as $310-330^{\circ} \mathrm{C}$ in the small-diameter core pins. Again, side walls evolve quite similarly and do not show major differences in flow and heat transfer conditions, thus suggesting a prevalence of the above cited effects related to the amount of die lubricant.

Simulation results also confirmed the direct relationship between the limited performance of the cooling channels and the choices related to spray cooling. When the die is opened, the thicker zones in the casting are still at temperatures just below the solidus temperature of the alloy and thus have poor mechanical properties. This can cause breakage or crushing due to the pressure of the ejector pins. In the past, the experience at the company had suggested to avoid this problem by increasing the amount of die lubricant. It can be foreseen that a more effective cooling deriving from conformal channels could increase cooling rates even in the more critical zones of the casting and thus reduce the needed amount of spray cooling, with beneficial effects on surface finish.

\section{DESIGN OF THE COOLING SYSTEM}

To verify the above considerations, the ejector die impression block was redesigned with a conformal 
cooling system, with no changes to the cover die half. To allow full interchangeability, the new tool had to match the holding block and the ejection system of the original die. Based on simulation results, the analysis of cooling issues suggested a preliminary layout of cooling channels, which was later refined along some redesign and simulation steps. Fig. 5a shows the new impression block and Fig. 5b shows the layout of conformal channels for a single impression. They include two parallel lines linked by four by-pass lines. The coolant (water as in the conventional die) flows from the inlet line on the gate side through the by-pass lines to the outlet line on the opposite side; the direction of flow helps balancing the difference of temperature between the two side walls of the casting, which may have an effect on the location of surface waves. By-pass lines are located on four parallel planes, yet they bend into three-dimensional shapes in order to conform to impression surfaces at very close distances (about $2.5 \mathrm{~mm})$.

Cross sections of channels were sized through calculations and simulations along the development steps of the tool. Inlet and outlet lines have uniform circular sections with $7 \mathrm{~mm}$ diameter, while bypass lines have elliptical sections with equivalent total area but with variable aspect ratios and orientations for an easier access to narrow recesses. The design of by-pass lines includes large radii to avoid thermal fatigue cracks that could be caused by sharp bends or edges. Simulations confirmed that flow rates are uniform through by-pass lines, flow rates and velocities are adequate to heat transfer requirements and coolant temperature increases uniformly and gradually along all by-pass lines.

The chance to build complex geometries by additive techniques suggested a further corrective action in order to improve cooling conditions. As previously noted and shown in Fig. 6a, the thicker bosses on the backside of the casting could be partially responsible of the uneven cooling rate. These details were cored out as shown in Fig. 6b, without changing any diameter and location of holes and without structural weakening of the bosses.

Further simulations were done after coring out the bosses in order to evaluate the impact of the new geometry of the casting. As an example of results, Fig. 7 compares the distribution of temperature in a section of the die at nearly half of programmed cooling time with conventional channels and conformal channels. Temperatures are nearly equal in the two options (around $150^{\circ} \mathrm{C}$ ) at a distance over 10-15 mm from impression surfaces; however, conformal channels reduce core temperature by over $50^{\circ} \mathrm{C}$ at the rounded ends of the casting and by over $20^{\circ} \mathrm{C}$ at the core pins (although they are not cooled from inside). For the conventional cooling system, temperatures are very close to those estimated by the first simulations on original part geometry; this seems to suggest that the redesign of the casting was much less beneficial on cooling performance than the introduction of conformal cooling channels. 


\section{FABRICATION OF TOOL BLOCKS}

The impression block in Fig. 5 was fabricated by an additive-manufacturing service company (Texer Design, Vazzola, Italy). According to common practice for injection molds, a hybrid construction strategy was chosen to reduce process and material costs: the block is made of two pieces separated at the dashed line in Fig. 8. The upper piece, which includes the cores and the conformal cooling channels, was built by selective laser melting (SLM) from powders of AISI H11 (DIN 1.2343) hotwork steel. The lower piece, which is $25 \mathrm{~mm}$ thick and includes the inlet and outlet ports for the coolant, was built by CNC machining from a blank made of the same steel. The main lines of the cooling system (Fig. 5) were placed on the parting plane to ease powder removal.

The lower piece was first milled and ground on the upper plane, from which metal powders were laser melted on a Concept Laser M1 system with a layer thickness of $0.03 \mathrm{~mm}$ (Fig. 9). An allowance of $0.3 \mathrm{~mm}$ was left for $\mathrm{CNC}$ finish milling after a thermal treatment. Additional machining work was needed to to adapt the holding block to the new impression block. The whole process took $180 \mathrm{~h}$, of which $91 \mathrm{~h}$ for the additive manufacturing phase.

\section{PRODUCTION TESTING}

Die casting tests were done on the SLM impression block to identify process settings suitable to the more effective cooling system and to evaluate possible reductions of surface waves and cooling time. Most process parameters were left unchanged to allow a comparison of results with former practice. The experimental plan was limited to a sequence of combinations between the two specific factors of interest, namely cooling time and amount of die lubricant. The time available for tests on the production line was not sufficient for a more comprehensive experiment including more factors (e.g. injection temperature, lubricant composition and die opening time) and disturbances (e.g. inlet coolant temperature depending on weather conditions).

Cooling time is the programmed delay between the end of the compression phase (which lasts 1.8 $\mathrm{s}$ after injection) and die opening (which lasts $5 \mathrm{~s}$ ). From the $4.5 \mathrm{~s}$ of the original process, conformal cooling allowed to reduce cooling time down to $1 \mathrm{~s}$. Once a cooling time was set on the machine, its feasibility was verified by running 15-20 cycles until thermal steady state was reached (verified by thermocouples on the die); castings manufactured from that point on were inspected to detect possible issues due to insufficient cooling, such as crushing of bosses due to ejector pins or breakage in runners during robot handling.

Lubrication is done by a cartesian sprayer with 16 nozzles, which apply a predetermined quantity of an oil-water mixture in a short time $(0.1 \mathrm{~s})$. Spray application can be repeated multiple times to vary the amount of lubricant per cycle. Conformal cooling allowed to try lower numbers of applications from the three of the original process down to just one. 
In summary, a full factorial experiment was not feasible due to the process constraints highlighted in Fig. 10. The time allotted for the experiment on the production line limited the total number of diecasting cycles to nearly 1200 , thus allowing no randomizations or replications of individual settings. This made it impossible to do a statistical analysis of the individual and combined effects of the two factors on surface finish.

For each combination of factors, a sample of 4 parts was randomly selected from the 60-80 castings manufactured in steady-state conditions. The amount of surface waves was observed on each part in the three zones A, B and C of Fig. 3; in each zone, the approximate length $K$ of the visible lines on part surface was evaluated. To control disturbance during length measurements, parts were brushed by a hand tool and put in a box under standard lighting conditions (daylight D65 and custom fluorescent TL 84).

The plots in Fig. 11 illustrate the effect of cooling conditions on the surface finish of the castings. For each setting, they include the amount of surface waves (total length $K_{\text {tot }}$ ) and their distribution along the different zones (fraction $K_{\mathrm{C}} / K_{\text {tot }}$ of total length observed in the side wall opposite the gate). With conformal cooling, the attempt to increase productivity with the same amount of spray cooling results in a reduction of surface defects to less than $50 \%$ at a cooling time of $2 \mathrm{~s}$. When aiming to a reduction of spray cooling, defects decrease to nearly $30 \%$ compared to conventional cooling. When increasing cooling time with minimum amount of lubricant, surface waves drop to an average of $10 \%$ compared to conventional cooling; such finish is potentially suitable to electroplating and high-gloss painting. The location of defects seems to especially depend on the amount of lubricant, whose reduction improves the surface finish more at the rounded ends than on the planar side wall.

The above plots show 95\% confidence intervals for the means of both responses at each setting. Regarding the amount of surface waves $\left(K_{\mathrm{tot}}\right)$, it is clearly noted that all settings based on the conformally cooled die (S1 to S6) achieve significantly lower mean values than the original setting 
based on the conventionally cooled die (S0). Such result was confirmed through t-test comparisons among settings. The normality of response values was also verified for all settings. When considering the setting as a seven-level factor, the significance of its effect was verified by analysis of variance of a suitably transformed response ( $\ln K_{\mathrm{tot}}$ ), which passed all needed tests on residuals (normality, homogeneity of variance).

In the selection of optimal process parameters, setting S6 is preferable for surface quality and settings S2 and S3 allow the maximum productivity at different levels of surface quality. Depending on the chosen condition, cycle time decreases by 1 to $3.5 \mathrm{~s}$ compared to conventional cooling, with a reduction from 5 to $20 \%$ on the $18 \mathrm{~s}$ of the original process. The related savings on process cost can be estimated from 15 to $40 \mathrm{k} €$ on each million of castings produced. Even considering the slight increase in tooling cost involved by the SLM-based process chain, it is difficult to evaluate the ultimate reduction of manufacturing cost per part in the lack of tool life data. However, the economic justification of the solution seems to be ensured regardless of specified surface finish.

A further benefit expected from the improvement of cooling performance is the reduction of shrinkage porosity, which is not critical for this product but could be for different ones. Such conjecture was confirmed through inspection of some samples, as it is clear when comparing the sections of two castings manufactured with conventional cooling (Fig. 12a) and conformal cooling (Fig. 12b). The inspected zone is a wall on one of the bosses on the backside of the part in proximity of a hole (tapped only in the original process). The decrease of porosity can be visually appreciated; it was estimated on the average from $1.5 \%$ to $0.5 \%$ in volume. As the inspected zone had not been modified in the redesign of Fig. 6, this improvement can be entirely attributed to the effect of the conformal cooling system.

\section{CONCLUSIONS}

The above results confirm that direct-metal additive manufacturing techniques such as SLM can be successfully used for the fabrication of die-casting dies. As for injection molds for plastics, the process chain fits easily into toolmakers' practice without compromises on die material and additional secondary operations, although with no significant compression of response time. It is also confirmed that conformal cooling channels give significant advantages: differently from injection molding, where they yield a dramatic reduction of cycle time and shrinkage defects, the more interesting opportunity is the chance of tuning the process at different trade-off levels between productivity and surface quality of castings. The increase of cooling rate reduces the need of spray cooling and thus allows to reduce the amount of lubricant sprayed on die surfaces, thus avoiding local premature freezing and consequent surface waves as well as contamination from thick lubricant layers at the interface between impression and casting. The quality of castings is further enhanced by a reduction of shrinkage 
porosity. This brings into question the common assumption that high-gloss surfaces and high structural integrities cannot be achieved on die castings with complex, hollow shapes.

Having provided a first experimental evidence to the above hypothesis is the main contribution of the present work, even if a scientific understanding of the involved phenomena will have to be pursued in future studies by analytic modeling and laboratory tests. Besides, the description of the case study has allowed to present technical data and details that are usually not documented in literature and will possibly be useful for further improvements to the process chain. These are concerned with either the design of the conformal cooling system (sizing and layout of channels as a result of simulation-based design iterations), the fabrication of the impression blocks (hybrid construction, machining allowance, manufacturing hours) and the testing of die performance (reduction of surface defects, cycle time and process cost).

The generalization of such results is limited by the choice of a single application case and by the difficulty of conducting extended tests on an industrial production line. Future work will have to extend the analysis to a wider set of variables related to both part design (projected size, height, thickness, form detail) and process conditions (injection and die temperatures, coolant and lubricant compositions). This will allow to build predictive models of surface finish in the different cooling conditions and quantitative criteria for the optimal planning of the process according to part geometry.

Die life testing is another field for future developments. The fact that the redesigned insert has been used at the company for nearly two thousand cycles without any wear or damage confirms that a SLM insert can be fully suitable to short-run manufacturing applications. Tests over several hundreds of thousands of cycles will help to understand if the tooling solution described in this paper has the potential to compete with conventional process chains in a serial production context.

\section{References}

[1] Karunakaran KP, Bernard A, Suryakumar S, Dembiski L, Taillandier G (2012) Rapid manufacturing of metallic objects. Rapid Prototyp J 18(4):264-280.

[2] Ahn DG (2011) Applications of laser assisted metal rapid tooling process to manufacture of molding and forming tools: state of the art. Int J Precis Eng Manuf 12(5):925-938.

[3] Sachs E, Wylonis E, Allen S, Cima M, Guo H (2000) Production of injection molding tooling with conformal cooling channels using the three-dimensional printing process. Polym Eng Sci 40(5):1232-1247.

[4] Xu X, Sachs E, Allen S (2001) The design of conformal cooling channels in injection molding tooling. Polym Eng Sci 41(7): 1265-1279.

[5] Dalgarno K, Stewart T (2001) Production tooling for polymer moulding using the RapidSteel process. Rapid Prototyp J 7(3):173-179. 
[6] Dalgarno KW (2001) Production grade tooling via layer manufacture. Rapid Prototyp J 7(4):203-206.

[7] Ilyas I, Taylor C, Dalgarno K, Gosden J (2010) Design and manufacture of injection mould tool inserts produced using indirect SLS and machining processes. Rapid Prototyp J 16(6):429-440.

[8] Liu J, Lu Z, Shi Y, Xu W, Zhang J (2010) Investigation into manufacturing injection mold via indirect selective laser sintering. Int J Adv Manuf Technol 48:155-163.

[9] Mayer S (2008) Optimised mould temperature control procedure using DMLS. Whitepaper, EOS GmbH, Krailling/Munich, Germany.

[10] Ruffner T (2012) Conformal cooling using DMLS. Whitepaper, GPI Prototype and Manufacturing Services Inc., Lake Bluff, IL.

[11] Rännar LE, Glad A, Gustafson CG (2007) Efficient cooling with tool inserts manufactured by electron beam melting. Rapid Prototyp J 13(3):128-135.

[12] Ahn DG, Park SH, Kim HS (2010) Manufacture of an injection mould with rapid and uniform cooling characteristics for the fan parts using a DMT process. Int J Precis Eng Manuf 11(6): 915-924.

[13] Wimpenny DI, Bryden B, Pashby IR (2003) Rapid laminated tooling. J Mater Process Technol 138:214-218.

[14] Williams RE, Walczyk DF, Dang HT (2007) Using abrasive flow machining to seal and finish conformal cooling channels in laminated tooling. Rapid Prototyp J 13(2):64-75.

[15] Yoo S, Walczyk DF (2007) A preliminary study of sealing and heat transfer performance of conformal channels and cooling fins in laminated tooling. Trans ASME J Manuf Sci Eng 129: 388-399.

[16] Yoo S (2008) Design of conformal cooling/heating channels for layered tooling. In Proc Int Conf Smart Manufacturing Application, April 9-11, 2008, Gyeonggi-do, Korea.

[17] Walczyk DF, Yoo S (2009) Design and fabrication of a laminated thermoforming tool with enhanced features. J Manuf Process 11:8-18.

[18] Ferreira JC, Mateus A (2003) Studies of rapid soft tooling with conformal cooling channels for plastic injection moulding. J Mater Process Technol 142:508-516.

[19] Knirsch JR (2007) Faster, less expensive dies using RSP tooling. J Mater Eng Perform $16(4): 432-439$.

[20] Saifullah ABM, Masood SH, Sbarski I (2011) Thermal-structural analysis of bi-metallic conformal cooling for injection moulds. Int J Adv Manuf Technol 62:123-133.

[21] Yao D, Chen SC, Kim BH (2008) Rapid thermal cycling of injection molds: an overview of technical approaches and applications. Adv Polym Technol 27(4):233-255.

[22] Xu RX, Sachs E (2009) Rapid thermal cycling with low thermal inertia tools. Polym Eng Sci 
[23] Wang G, Zhao G, Li H, Guan Y (2011) Multi-objective optimization design of the heating/cooling channels of the steam-heating rapid thermal response mold using particle swarm optimization. Int J Therm Sci 50:790-802.

[24] Au KM, Yu KM (2007) A scaffolding architecture for conformal cooling design in rapid plastic injection moulding. Int J Adv Manuf Technol 34:496-515.

[25] Au KM, Yu KM (2011) Modeling of multi-connected porous passageway for mould cooling. Comput Aided Des 43:989-1000.

[26] Au KM, Yu KM, Chiu WK (2011) Visibility-based conformal cooling channel generation for rapid tooling. Comput Aided Des 43:356-373.

[27] Wang Y, Yu KM, Wang CCL, Zhang Y (2011) Automatic design of conformal cooling circuits for rapid tooling. Comput Aided Des 43:1001-1010.

[28] Lin ZC, Chou MH (2002) Design of the cooling channels in nonrectangular plastic flat injection mold. J Manuf Sys 21(3):167-186.

[29] Park HS, Pham NH (2009) Design of conformal cooling channels for an automotive part. Int J Automot Technol 10(1):87-93.

[30] Park HS, Dang XP (2010) Optimization of conformal cooling channels with array of baffles for plastic injection mold. Int J Precis Eng Manuf 11(6):879-890.

[31] Dang XP, Park HS (2011) Design of U-shape milled groove conformal cooling channels for plastic injection mold. Int J Precis Eng Manuf 12(1):73-84.

[32] Ahari H, Kajepour A, Bedi S (2011) Manufacturing optimization of laminated tooling with conformal cooling channels. Rapid Prototyp J 17(6):429-440.

[33] Altaf K, Raghavan VR, Rani AMA (2011) Comparative thermal analysis of circular and profiled cooling channels for injection mold tools. J Appl Sci 11(11):2068-2071.

[34] Furumoto T, Ueda T, Amino T, Kusunoki D, Hosokawa A, Tanaka R (2012) Finishing performance of cooling channel with face protuberance inside the molding die. J Mater Process Technol 212(10):2154-2160.

[35] Dimla DE, Camilotto M, Miani F (2005) Design and optimisation of conformal cooling channels in injection moulding tools. J Mater Process Technol 164-165:1294-1300.

[36] Hassan H, Regnier N, Lebot C, Pujos C, Defaye G (2009) Effect of cooling system on the polymer temperature and solidification during injection molding. Appl Therm Eng 29:17861791.

[37] Hassan H, Regnier N, Le Bot C, Defaye G (2010) 3D study of cooling system effect on the heat transfer during polymer injection molding. Int J Therm Sci 49:161-169.

[38] Zheng Z, Zhang H, Wang G, Qian Y (2011) Finite element analysis on the injection molding 
[39] Norwood AJ, Dickens PM, Soar RC, Harris R, Gibbons G, Hansell R (2004) Analysis of cooling channel performance. Int J Comput Integr Manuf 17(8):669-678.

[40] Takayama T, Takahashi T, Sano M (2004) Cooling arrangement for die-casting metal mold. US Patent No 6,698,496 B2.

[41] Pessard E, Mognol P, Hascoët JY, Gerometta C (2008) Complex cast parts with rapid tooling: rapid manufacturing point of view. Int J Adv Manuf Technol 39:898-904.

[42] Mohammed J (2007) Manufacturing die casting molds via Direct Metal Deposition (DMD). SME Tech Pap TP07PUB70.

[43] Knirsch JR (2008) Prototype die casting using RSP technology. SME Tech Pap TP08PUB37.

[44] Bounds S, Davey K, Hinduja S (2000) An experimental and numerical investigation into the thermal behavior of the pressure die casting process. Trans ASME J Manuf Sci Eng 122:90-99.

[45] Clark LD, Davey K, Hinduja S (2001) Novel cooling channel shapes in pressure die casting. Int J Numer Method Eng 50:2411-2440.

[46] Lin JC (2003) The optimal design of a cooling system for die-casting die with a free form surface. Int J Adv Manuf Technol 21:612-619.

[47] Vinarcik EJ (2003) High integrity die casting processes. John Wiley \& Sons, New York.

[48] Liu GW, Morsi YS, Clayton BR (2000) Characterisation of the spray cooling heat transfer involved in a high pressure die casting process. Int J Therm Sci 39:582-591.

[49] Sabau AS, Wu Z (2007) Evaluation of a heat flux sensor for spray cooling for the die casting processes. J Mater Process Technol 182:312-318.

[50] Sabau AS, Dinwiddie RB (2008) Characterisation of spray lubricants for the high pressure die casting processes. J Mater Process Technol 195:267-274.

[51] Ferreira JC (2006) A study of advanced die-casting technology integrating CAD/RP/FEA for Zn casting. Int J Adv Manuf Technol 31:235-243.

\section{List of figures}

Fig. 1: Handle cover

Fig. 2: Ejector die impression block with conventional cooling channels

Fig. 3: Appearance and location of surface waves

Fig. 4: Cooling simulation of the original process

Fig. 5: Redesigned impression block with conformal cooling channels

Fig. 6: Redesign of details in the casting

Fig. 7: Thermal sections: a) with conventional channels, b) with conformal channels

Fig. 8: Hybrid construction of the impression block 
Fig. 9: Fabrication of the impression block by SLM

Fig. 10: Experimental plan

Fig. 11: Amount and distribution of surface waves under different cooling conditions

Fig. 12: Reduction of shrinkage porosity 
Figure 1

Click here to download Figure: Fig1.eps

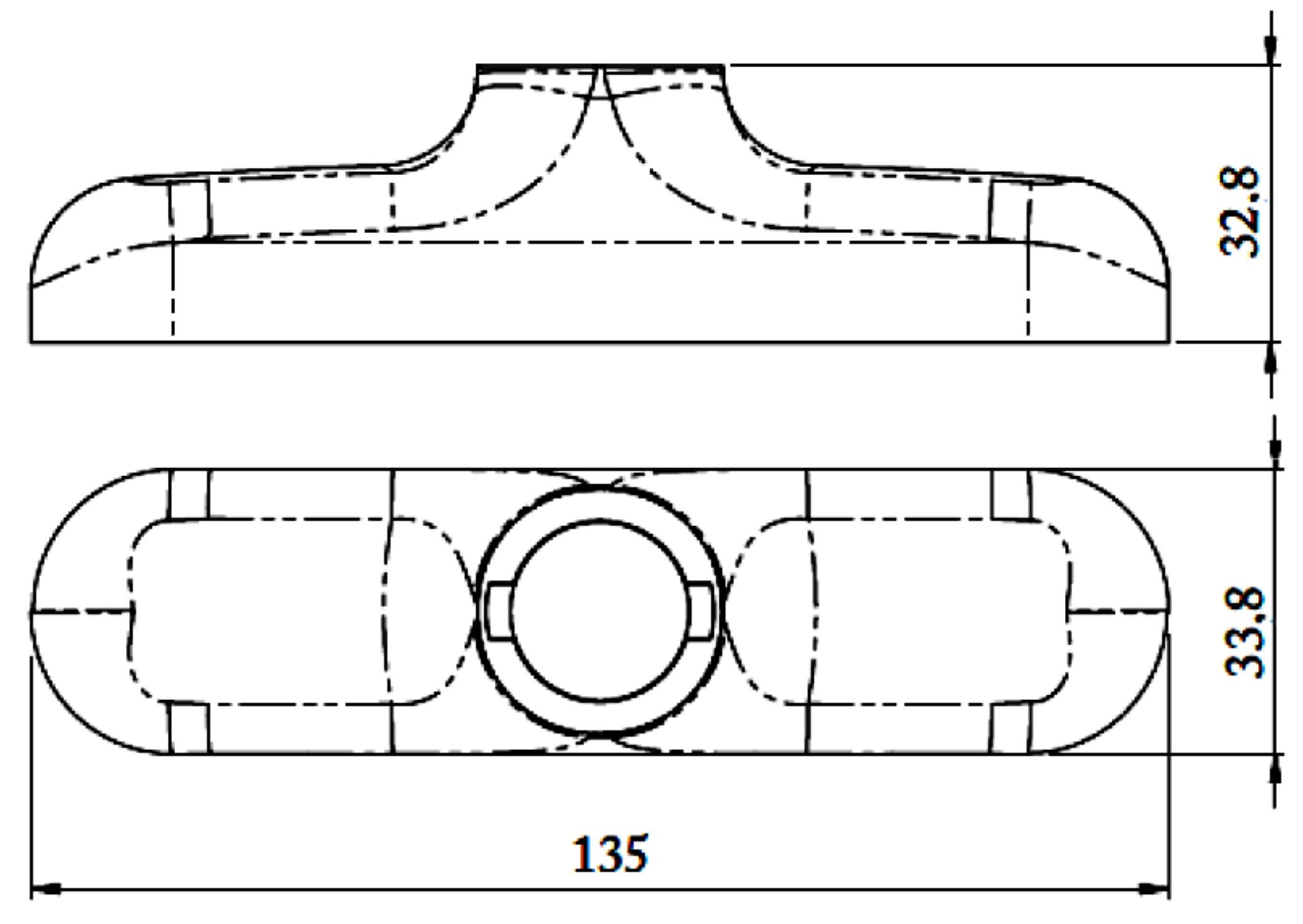



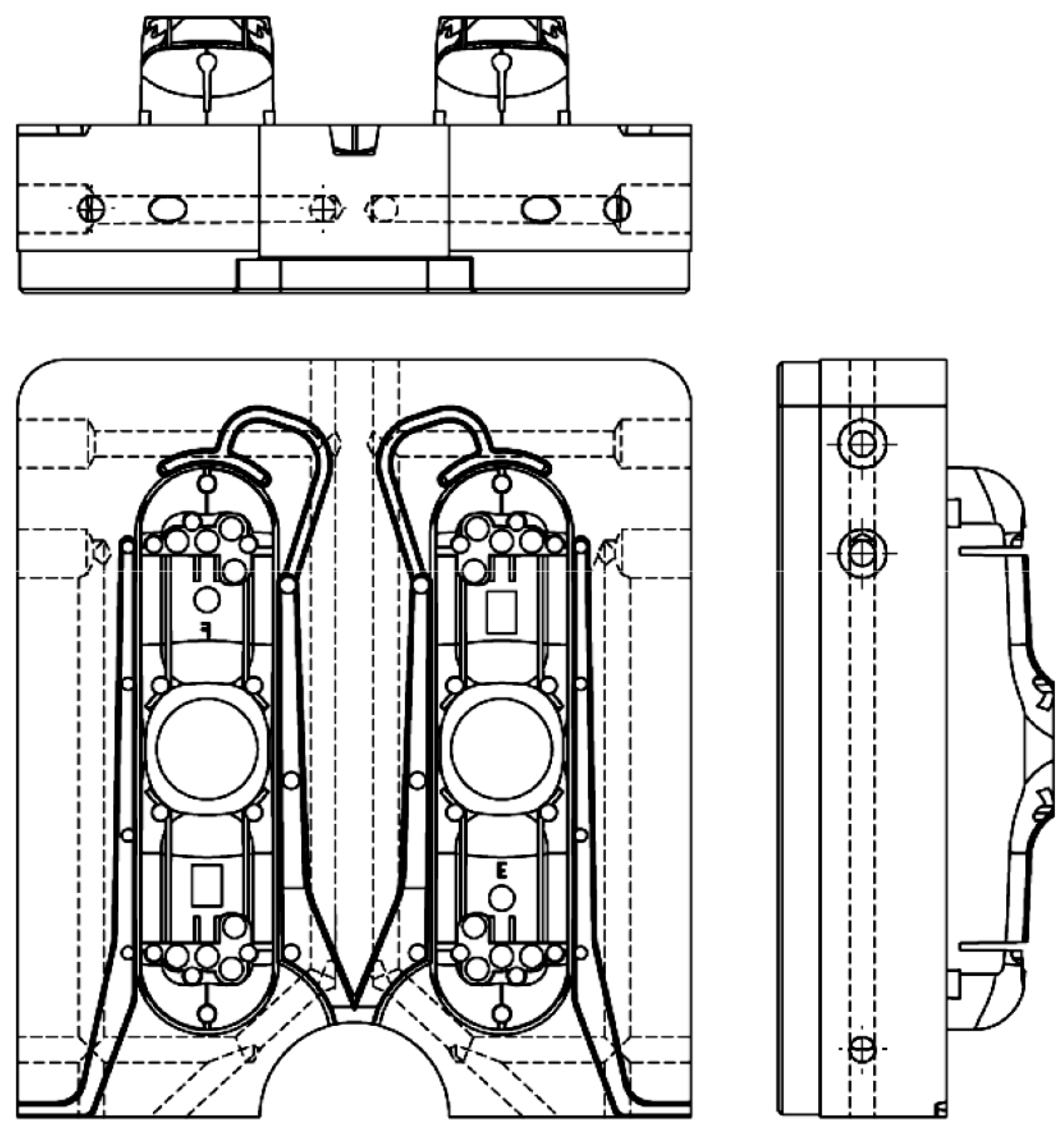
Figure 3
Click here to download Figure: Fig3.eps
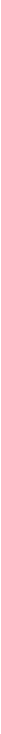
Figure
Click here to download Figure: Fig4.eps

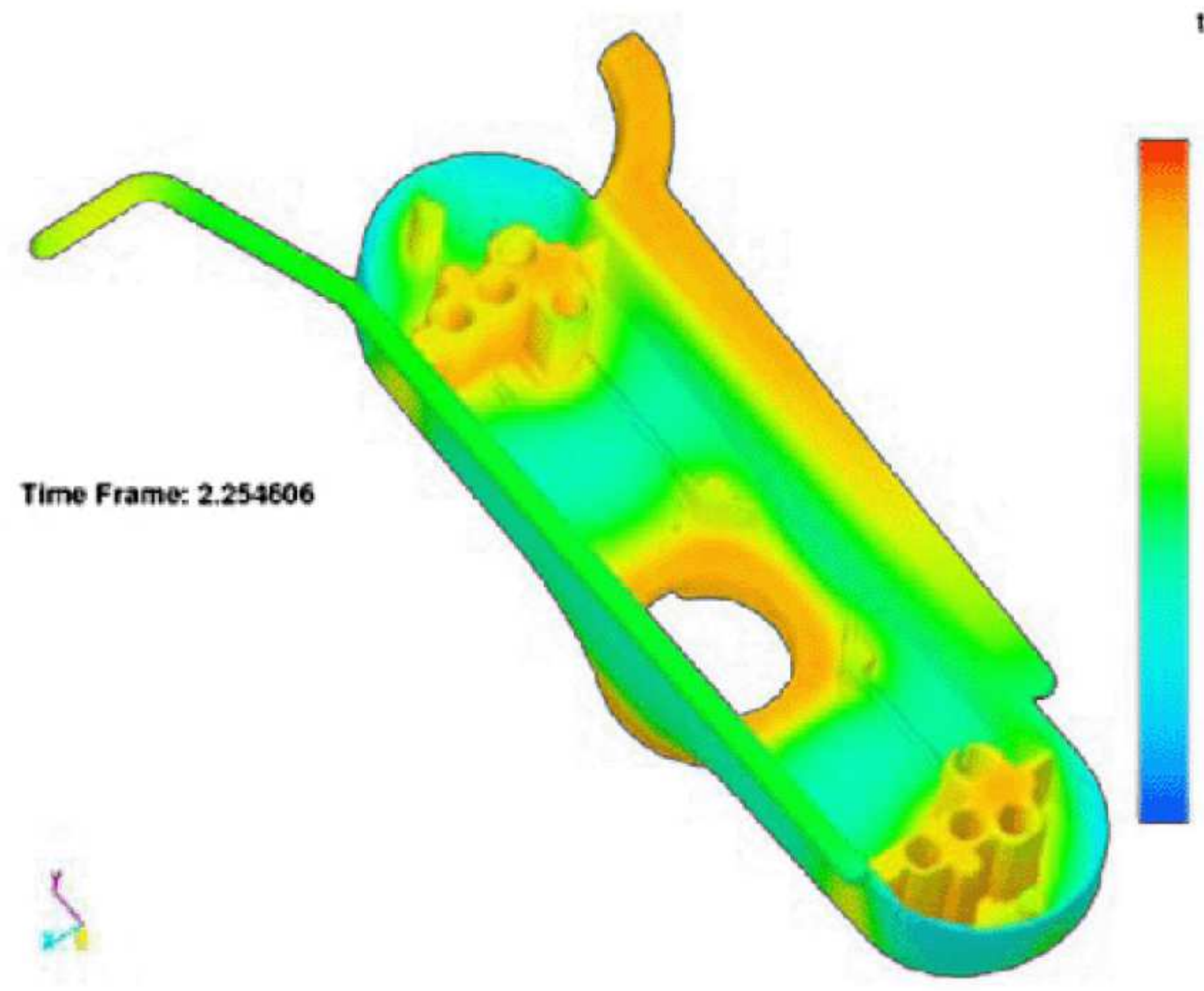

633.000

644.167

605.333

566.500

527.667

490.633

450.000 
Figure 5

Click here to download Figure: Fig5.eps

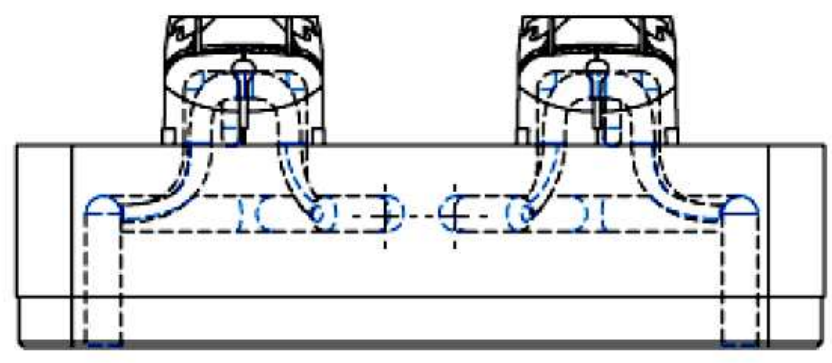

a)
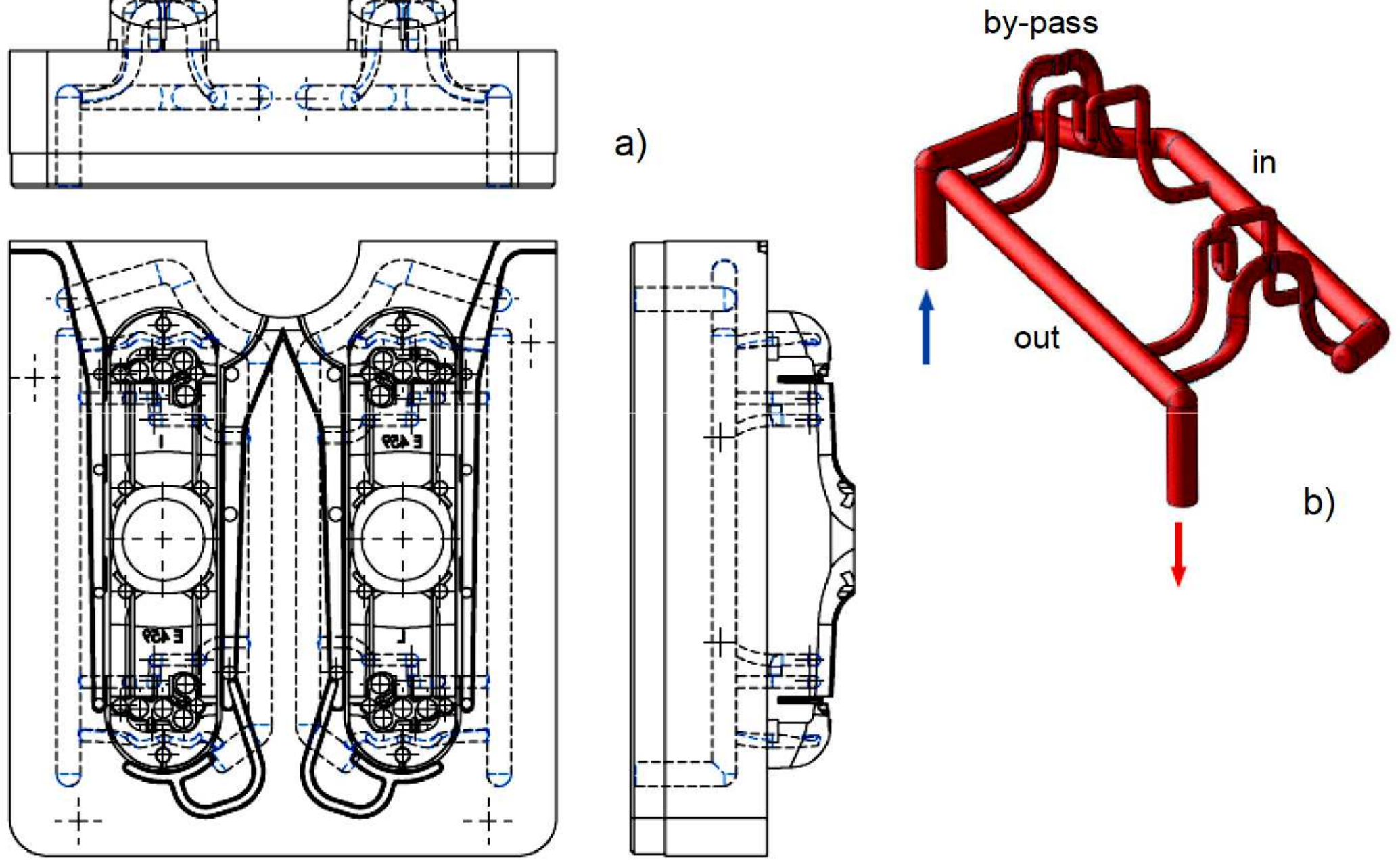
Figure 6
Click here to download Figure: Fig6.eps
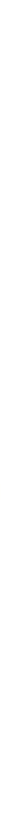


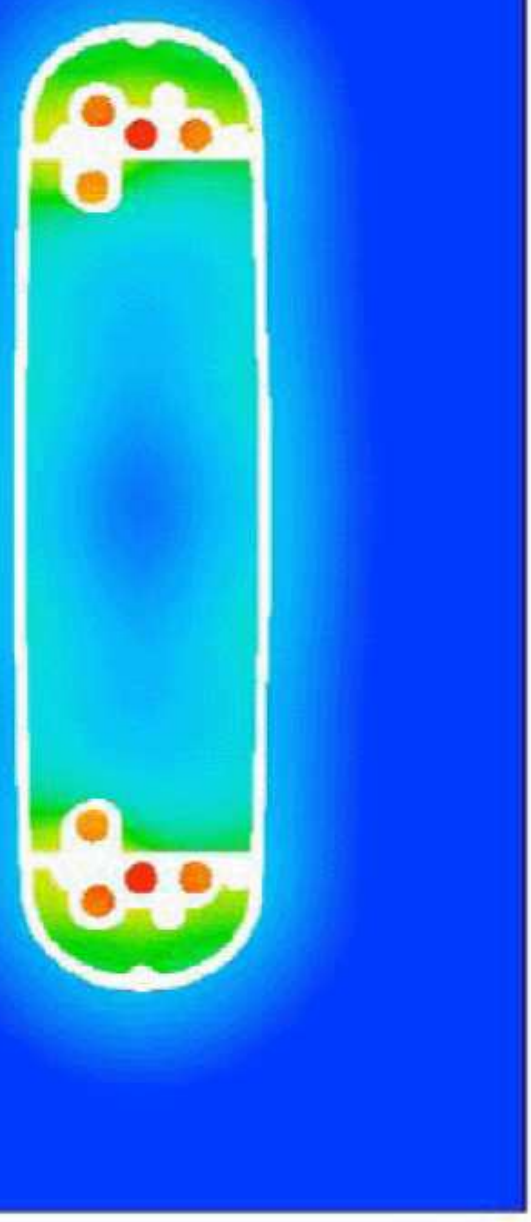

583
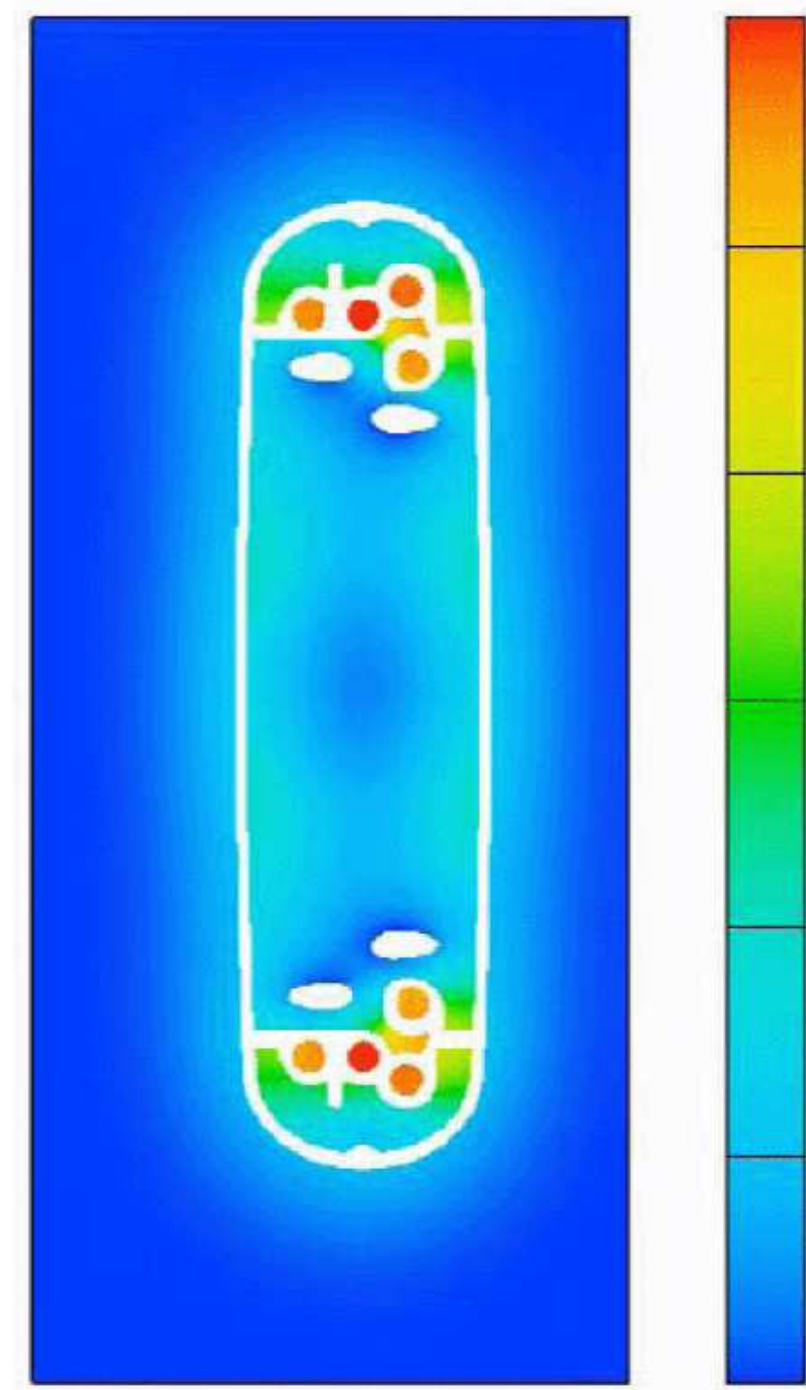
Figure 8

Click here to download Figure: Fig8.eps

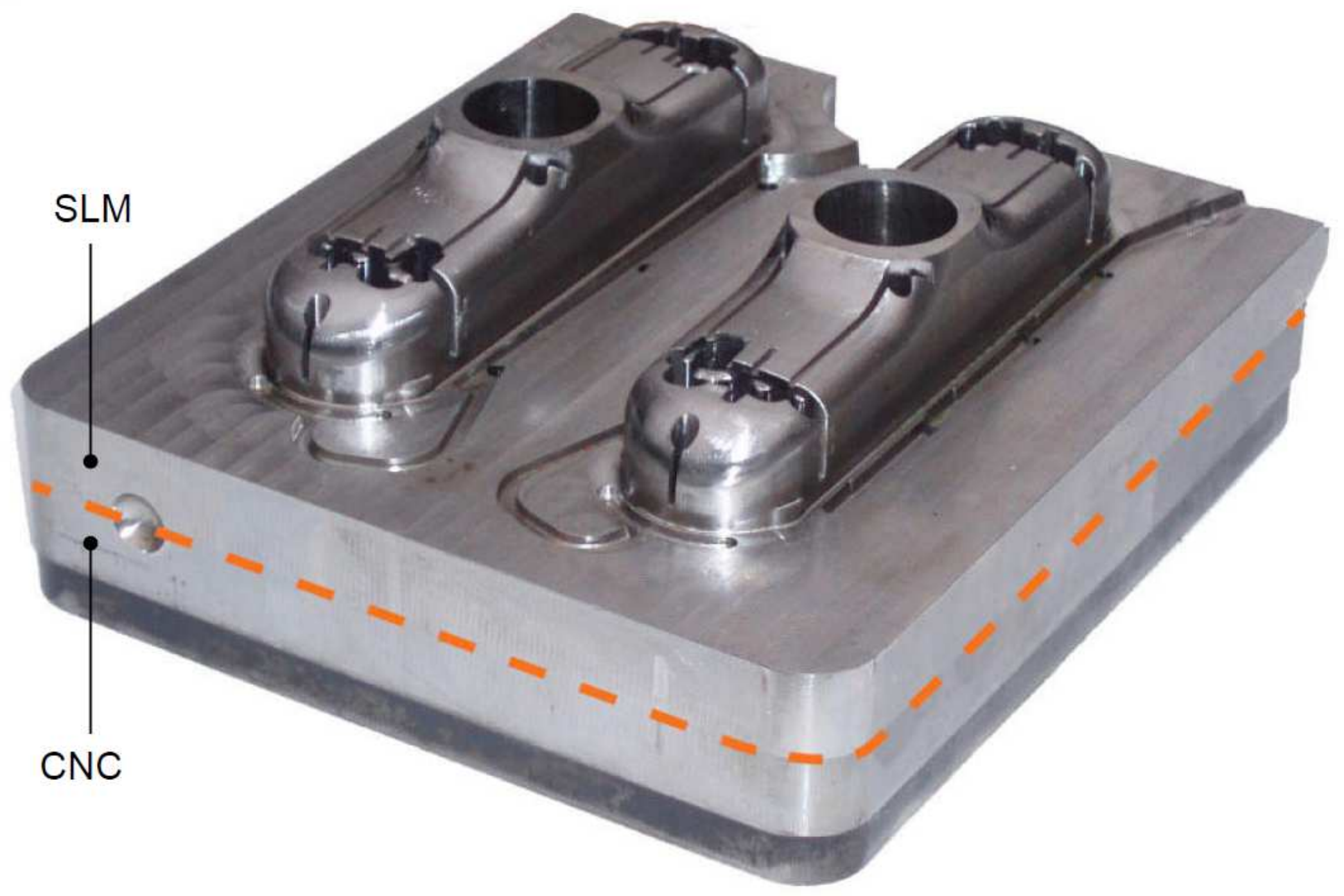


Figure 9

Click here to download Figure: Fig9.eps

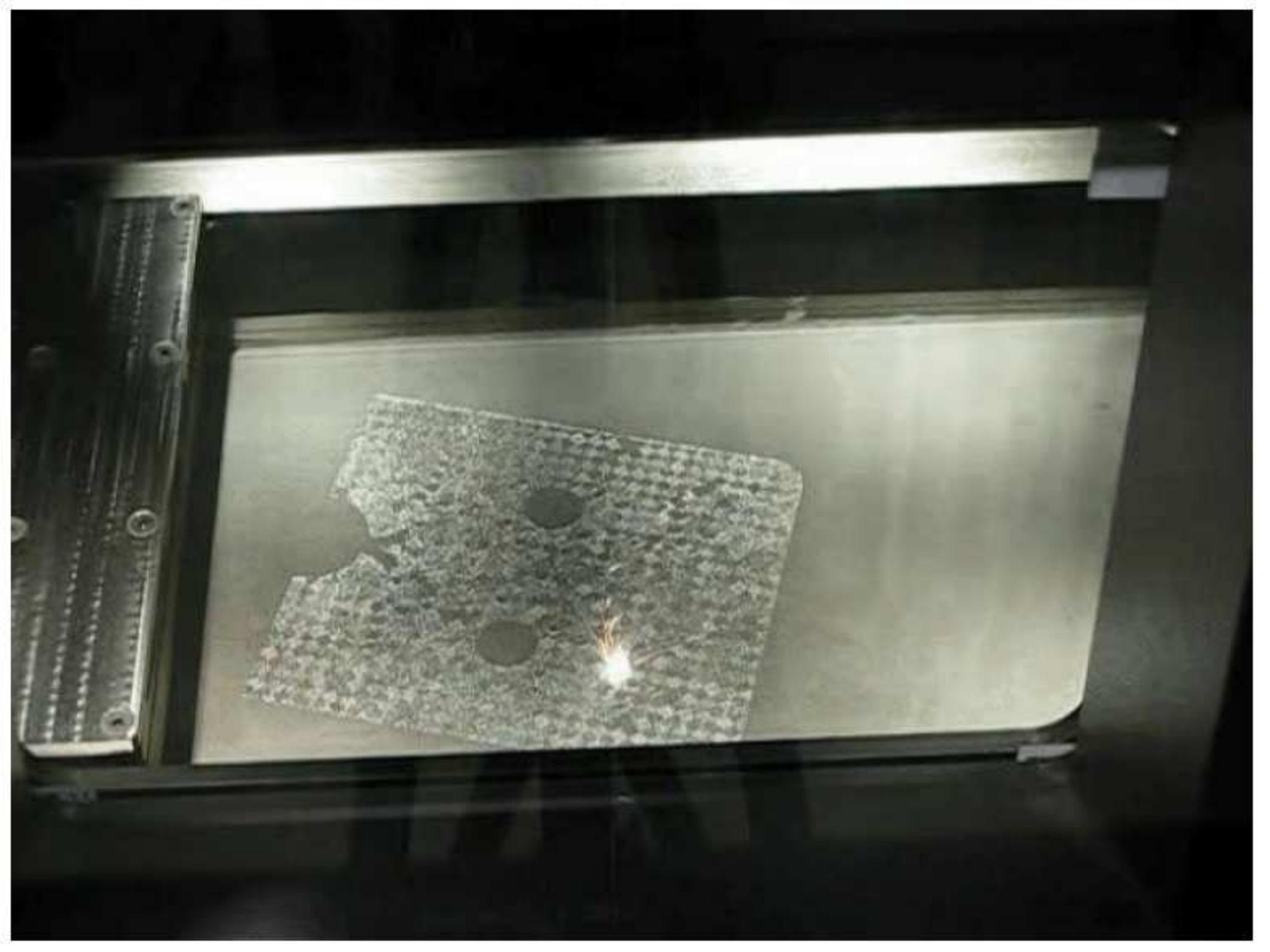




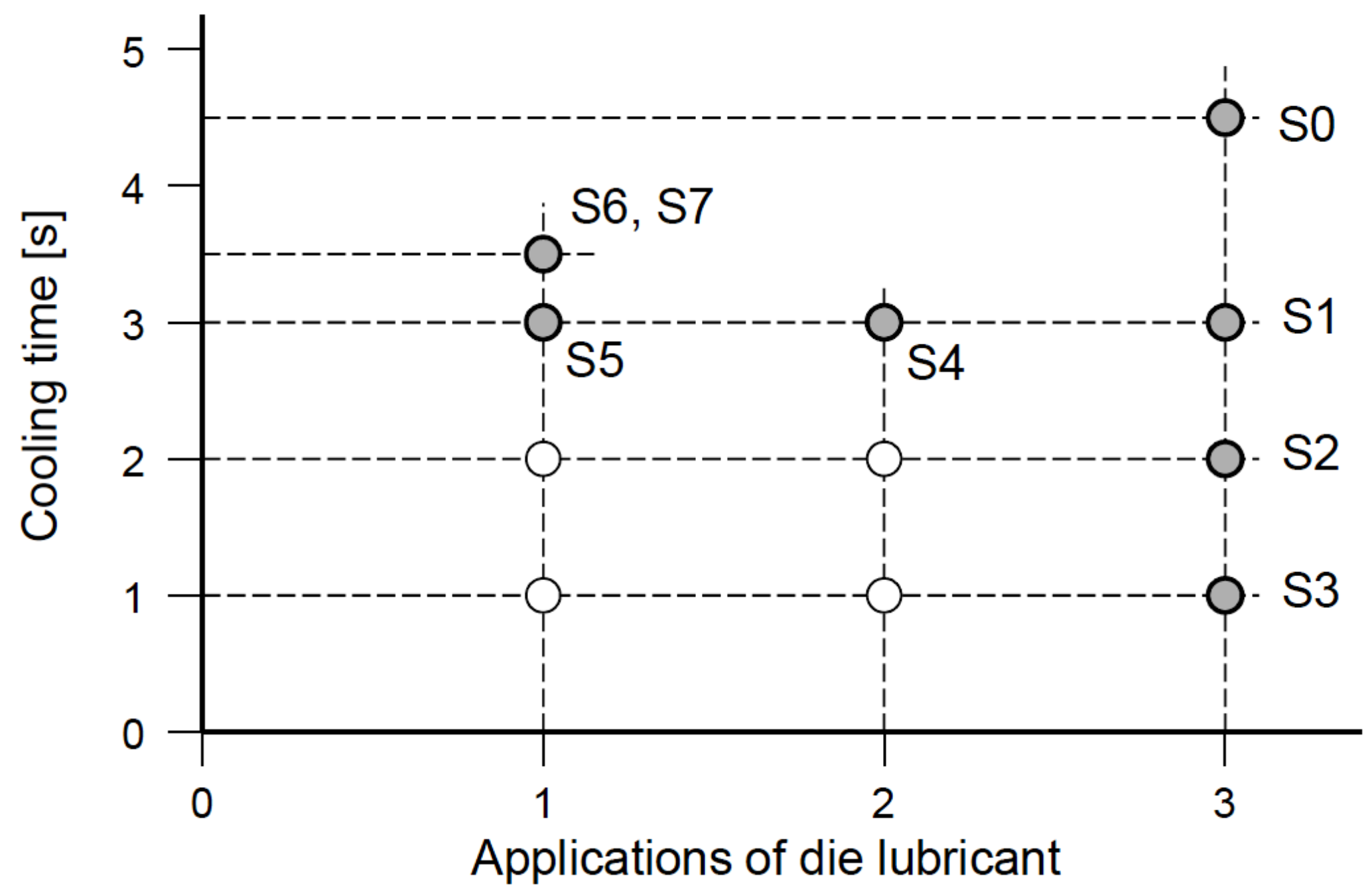




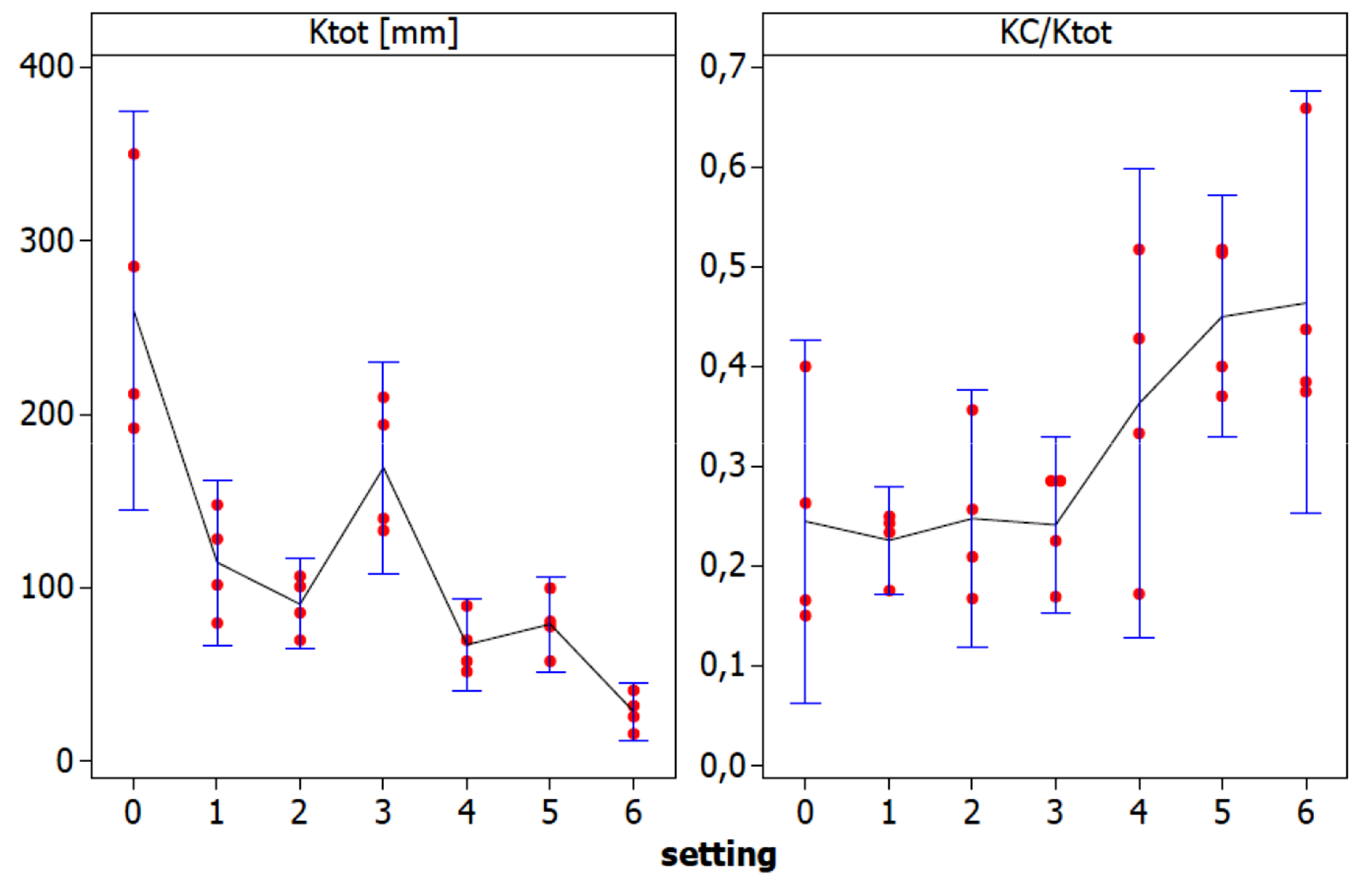


Figure 12

Click here to download Figure: Fig12.eps
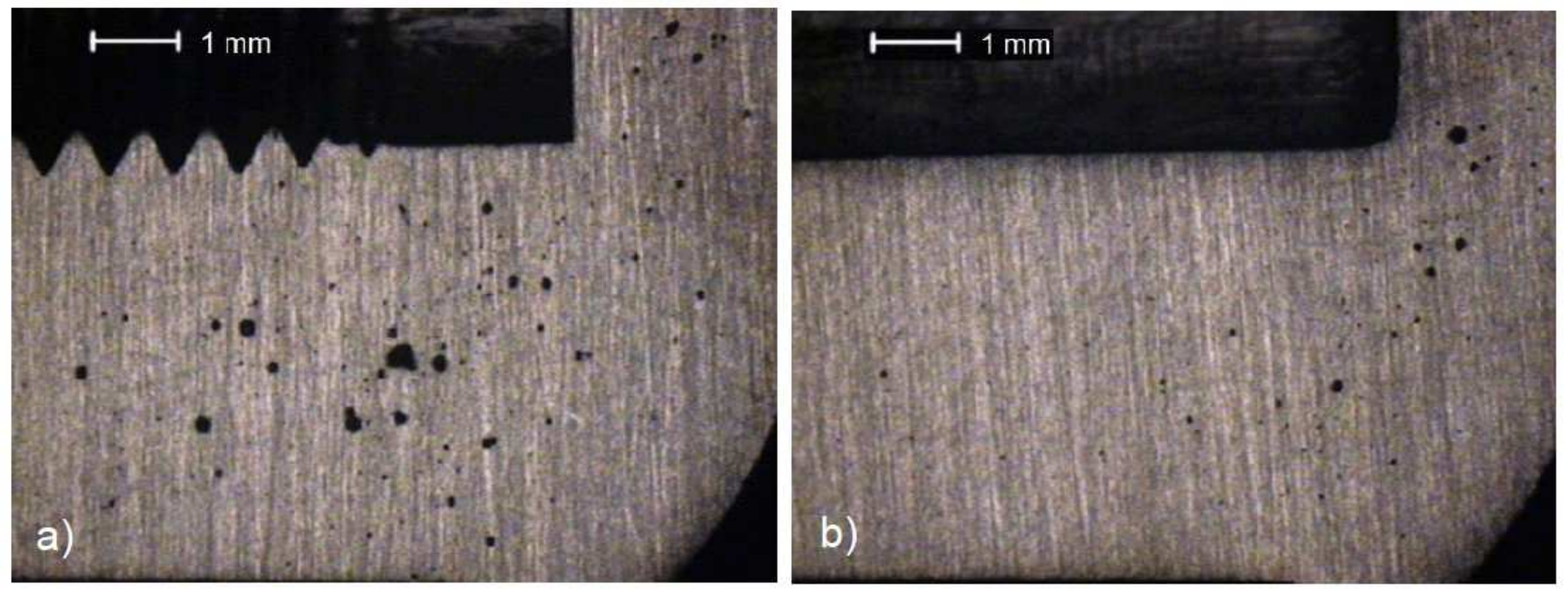

b) 